EESTI NSV TEADUSTE AKADEEMIA TOIMETISED. 22, KOIDE KEEMIA * GEOLOOGIA. 1973, NR. 2

ИЗВЕСТИЯ АКАДЕМИИ НАУК ЭСТОНСКОИ ССР. ТОМ 22 ХИМИЯ * ГЕОЛОГИЯ. 1973, № 2

удК 546.131

Т. КААЛ, К. ЛЭЭТС

\title{
ПОЛУЧЕНИЕ ЛАВАНДУЛОЛА ИЗ ДИМЕРА ГИДРОХЛОРИДА ИЗОПРЕНА
}

T. KAAL, $K$. LAATS. LAVANDULOOLI SAAMINE ISOPREENI HUDROKLORIIDI DIMEERIST

T. KAAL, K. LAATS. PREPARATION OF LAVANDULOL FROM ISOPRENE HYDROCHLORIDE DIMER

Ранее уже сообщалось, что при теломеризации изопрена с его гидрохлоридами в некоторой степени $(10-15 \%)$ происходит димеризация гидрохлоридов с образованием дихлорида 2,6-диметил-3-хлорметилгептен-5-хлора-2 [']. Этот димер получен также А. А. Петровым и М. Л. Генусовым $\left.{ }^{2}\right]$ из гидрохлорида изопрена в хлористом метилене в присутствии $\mathrm{SnCl}_{4}$. Дегидрохлорирование дихлорида спиртовой $\mathrm{KOH}$ привело к образованию лавандулилхлорида (2,6-диметил-3-хлорметилгептадиена-1,5). Однако лавандулол из этого хлорида не был получен. Недавно японскими авторами [3] показано, что галогениды лавандулола не подвергаются омылению; они могут быть превращены в соответствующий спирт косвенным путем, а именно окислением образующихся из них магнийорганических соединений.

Нами найдено, что получить лавандулол можно значительно проще, превращая димер гидрохлорида изопрена в упомянутый спирт без промежуточной стадии дегидрохлорирования. Отщепление молекулы хлористого водорода происходит при образовании магнийорганического соединения:

$$
\mathrm{C}_{10} \mathrm{H}_{18} \mathrm{Cl}_{2} \underset{-\mathrm{HCl}}{\stackrel{\mathrm{Mg}}{\longrightarrow}} \mathrm{C}_{10} \mathrm{H}_{17} \mathrm{MgCl} \stackrel{\mathrm{O}_{3}}{\longrightarrow} \mathrm{C}_{10} \mathrm{H}_{17} \mathrm{OMgCl} \stackrel{\mathrm{H}_{2} \mathrm{O} . \mathrm{H}^{+}}{\longrightarrow} \mathrm{C}_{10} \mathrm{H}_{17} \mathrm{OH}
$$

Частично отщепляется также вторая молекула $\mathrm{HCl}$, о чем свидетельствует значительное количество терпеновых углеводородов в продукте реакции. Содержание спиртов в полученных продуктах (по активному водороду) составляет $40-45 \%$. Оно не повышается и при проведении реакции с лавандулилхлоридом вместо димера гидрохлорида изопрена. Образовавшиеся спирты отделялись от углеводородов через борный эфир $\left\lceil^{4}\right\rceil$ и анализировались при помощи газо-жидкостной хроматографии (ГЖХ). Как видно из хроматограммы (рис. 1), продукт реакции состоит из шести изомерных спиртов с преобладанием 3-го компонента. Последний был выделен из смеси при помощи препаративной газо-жидкостной хроматографии (ПГЖХ). Его ИК-спектр не отличался от ИК-спектра лавандулола, приведенного В. Куном и Х. Шинцем [ ${ }^{5}$. Остальные компоненты выделить в чистом виде не удалось. Они, по всей вероятности, представляют собой изомеры лавандулола с другим расположением двойных связей. Теоретически, помимо лавандулола $(2,6$-диметил-3-метилолгептадиена-1,5), возможно образование 2,6-диметил-3метилолгептадиенов- 1,4 (цис- и транс-); - 1,$6 ;-1,5 ;-2,6 ;-3,6$ и -4,6 (цис- 
и транс-). Полученный при гидрировании смеси спиртов на окиси платины тетрагидролавандулол, по данным ГЖХ, является индивидуальным веществом.

\section{Экспериментальная часть}

1. Получение лавандулола. K 12 г магниевых стружек, покрытых слоем безводного тетрагидрофурана и помещенных в двухгорлую круглодонную колбу емкостью $0,5 \Omega$, снабженную обратным холодильником, капельной воронкой и хлоркальциевой трубкой, для начала реакции прибавляли 1 мл бромистого этила в 50 мл тетрагидрофурана и затем 52 г димера гидрохлорида изопрена (т. кип. $86-90^{\circ} \mathrm{C} / 4 \mu м, d_{4}^{20} 1,0238$ и $n_{D}^{20}$ 1,4791) в 300 мл тетрагидрофурана. После замедления реакции колбу нагревали на водяной бане до полного прекращения реакции. Через охлажденный льдом продукт реакции в течение 6 пропускали ток сухого кислорода. Затем бо́льшую часть тетрагидрофурана отгоняли в вакууме и продукт реакции разлагали $5 \%$-ным раствором $\mathrm{HCl}$. Образовавшийся терпеновый спирт экстрагировали эфиром, промывали $10 \%$-ным раствором соды и высушивали над безводным поташом. После перегонки в вакууме получили 37,9 г продукта с т. кип. $60-95^{\circ}(2$ мм), содержащего $41 \% \mathrm{C}_{10} \mathrm{H}_{17} \mathrm{OH}$ (по активному водороду). Выход спиртов $40,3 \%$ от теоретического. Очисткой через борный эфир получили 10,4 г спиртов с т. кип. $77-80^{\circ}(5$ мм $), d_{4}^{20} 0,8780$ и $n_{D}^{20} \quad 1,4667$.

Из 10,7 г лавандулилхлорида ['] и 1,5 г магния в 150 мл тетрагидрофурана по описанной методике получили 7,2 г продукта, из которого через борный эфир выделили 2,4 г спиртов с т. кип. 96-99 (11 мм), $d_{4}^{20} 0,8791$ и $n_{D}^{20} \quad 1,4698$.

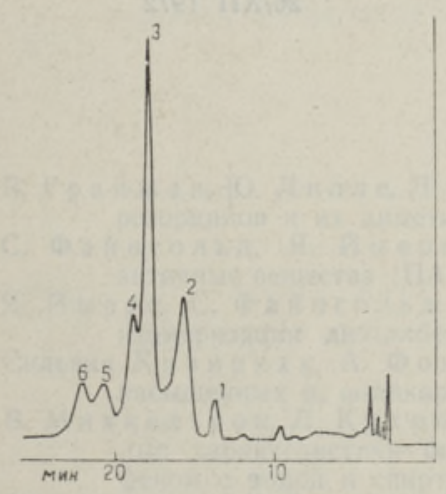

Рис. 1. Хроматограмма спиртов, полученных из димера гидрохлорида изопрена. «Хром-1», колонка 5 м, $\varnothing ~ 4,5$ мм, заполненная $3 \%$ этиленгликольадипата на хромосорбе $W$ (30-60 меш), рабочая температура $162^{\circ} \mathrm{C} .3$ - лавандулол, $1,2,4,5,6$ - не идентифицированы.

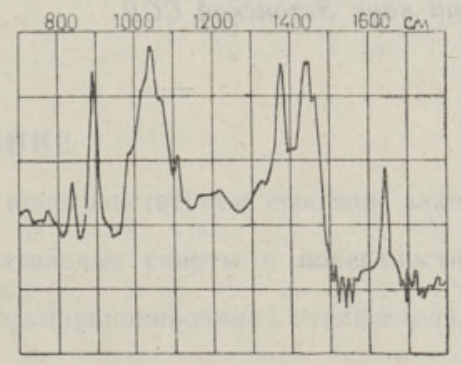

Рис. 2. Инфракрасный спектр лавандулола. Прибор UR-10. раствор в $\mathrm{CCl}_{4}$.

На рис. 1 приведена хроматограмма спиртов, полученных из димера гидрохлорида изопрена. Главный компонент (пик 3) выделили из смеси при помощи ПГЖХ при $180^{\circ} \mathrm{C}$ на колонке длиной 5 и диаметром 10 мм, заполненной $20 \%$ этиленгликольадипата на поролите $(0,25-0,31$ мм $)$. Полученный лавандулол имел $n_{D}^{2 n} 1,4691$. Его ИК-спектр приведен на рис. 2.

Хроматограмма спиртов, полученных из лавандулилхлорида, мало отличалась от приведенной выше хроматограммы. 
Данные литературы для лавандулола [6]: т. кип. $94-95^{\circ}$ (13 мм), $d_{4}^{17} \quad 0,8785, n_{D}^{17} \quad 1,4683$.

2. Получение тетрагидролавандулола. 0,7 г спиртов, полученных из димера гидрохлорида изопрена, прогидрировали в «утке» в $10 \mathrm{M} \Omega$ ледяной уксусной кислоты на 30 ме окиси платины согласно [7]. Уксусную кислоту нейтрализовали раствором соды. Продукт экстрагировали эфиром и высушивали поташом. Перегонкой в вакууме получили 0,4 г тетрагидролавандулола $\left.{ }^{8}\right]$ с $n_{D}^{20}$ 1,4419. По данным ГЖХ чистота $-93 \%$.

\section{Выводы}

1. Осуществлен синтез лавандулола из димера гидрохлорида изопрена.

2. Установлено, что, помимо основного продукта, образуются и другие изомерные спирты.

\section{ЛИ Т Е Р А Т У Р А}

1. Л ээ т с К. В., ЖОХ, 28, 3096 (1958); К а а л Т., Л ээ т с К., Изв. АН ЭССР, Хим. Геол., 21, 269 (1972).

2. Петров А. А., Генусов М. Л., ЖОрХ, 1, 2105 (1965).

3. Ta ka be K., Kat a giri T., T a nak a J., Nippon Kagaku Zasshi, 90, 943 (1969).

4. Gildemeister E., H of $\mathrm{fm}$ a n $\mathrm{n}$ Fr., Die ätherischen Ole, Band II, S. 287, Akademie-Verlag, Berlin, 1960.

5. Kuhn W., S chin z H., Helv. Chim. Acta, 35, 2008 (1952).

6. Schinz H., S eidel C. F., Helv. Chim. Acta, 25, 1572 (1942).

7. S ch in z H., B our qui in J.-P., Helv. Chim. Acta, 25, 1591 (1942).

8. S ch in z H., S chä p p i G., Helv. Chim. Acta, 30, 1483 (1947).

Институт химии

Академии наук Эстонской ССР
Поступила в редакцию 26/XII 1972 